\title{
Concepts, Present Status, Prospective and Myth and Reality of Organic Farming with Special Reference to Indian Context
}

\author{
Prakash Yadav ${ }^{1 *}$, T. Pandiaraj ${ }^{1}$, Vimlesh Kumar ${ }^{1}$, Vikash Yadav ${ }^{2}$ and Priyanka Singh ${ }^{3}$ \\ ${ }^{1}$ College of Agriculture, AcharyaNarendra Deva University of Agriculture and Technology, \\ Kotwa, Azamgarh-276001, UP, India \\ ${ }^{2}$ Central Horticulture Experimental Station (ICAR), Vejalpur, Godhra, Gujarat, India \\ ${ }^{3}$ Acharya Narendra Deva University of Agriculture and Technology, Kumarganj, \\ Ayodhya, UP, India \\ *Corresponding author
}

\section{A B S T R A C T}

\section{Keywords}

Exports, Myth and

Reality, Potential areas, Status,

Strategies

\section{Article Info}

Accepted:

28 July 2020

Available Online:

10 August 2020
India produces a massive variety of agricultural crops including cereals, oilseeds and pulses. The Green Revolution has been the keystone of India's agricultural achievement to produce more food production. To increase productivity, blanket application of a huge capacity of chemical fertilizers is being followed keeping the health aspect at bay. Hence, an alternative technique of farming system is of urgent need which could assure the needs of increased food production with providing defense against several potential health issues. Organic farming has been confirmed as a key to both of these problems. In addition, since the need for the pre-requisites for organic agriculture is less as contrast to chemical farming, as a result, in a country like India where the agriculture is highly influenced by the vagaries of different biotic and abiotic factors, organic farming is competent adequate to give economic security to the small and marginal farmers as well. However, with the strategy plans implemented by the government of India to support organic farming about the initiation, implementation and the selling of organic food products as well as the growing demand of the organic products in the domestic as well as international market, there is abundant scope for organic food industries to increase and generate profits for strengthening the Indian economy.

\section{Introduction}

It is optimistically realistic that India had perspective an incredible growth in agricultural production in the epoch of green revolution. Food grain production, which stood at a mere 50 million tons at the moment of independence, had increased roughly six times to 291.95 million tons by the end of 2018-19 (Press Information Bureau, GOI, 2020) from 195 million hectares of gross cultivated area in country. The Green Revolution has been the keystone of India's agricultural achievement, transforming 
country from the arena of food deficiency to self-sufficiency by employ of high yielding varieties and higher level of inputs of fertilizers and pesticides (Roychowdhury et al., 2013).

The excess/indiscriminate use of pesticides and fertilizers has led to the entry of harmful compounds into food chain, death of natural enemies and deterioration of surrounding ecology (Chitale et al., 2012). Injustice use of pesticide has resulted in grave health issues to human and his surrounding environment. Further, in last five decades, huge quantity of fertilizers and pesticides have been using and accomplished on plateau and diminishing low of return start to work (Venkateswarlu et al., 2008), as a result, more inputs (fertilizer and pesticides) have to apply to obtain little elevate in production which cause second generation problem and few of such epitome examples are some regions of Punjab (cancer belt of country) and endosulfan story of cashew plantations area in Kerala (proving finding of Rachel Carson's Silent Spring was published in 1962). In addition, pesticides in ideal condition lethal for target group only, for non-target group and human, it is safe but this principle is not followed strictly and indiscriminate use of these chemicals put human life and ecosystem health on verge (Aktar et al., 2009).

Hence, enhancement and maintenance of system productivity and resource quality is essential for sustainable agriculture. Prior to 1965, our country followed traditional farming practice without chemical fertilizers and pesticides. Most of developed countries and some developing nations are going back to organic farming practice during the last two decades because of diverse problems raised in conventional farming. Organic farming is solitary amongst the widescale of production methods that are caring of the environment. Organic farming is panacea to many of these problems since this system assists to maintain soil health and successfully manage pest by enhancing natural processes and sequences in harmony with environment.

\section{Concept and objectives of organic farming}

Organic farming is generally envisaged as the strike of synthetic inputs and their substitute by organic alternatives i.e. use of organic manures and natural methods of plant protection instead of using synthetic fertilizers/pesticides. But this is not true (Bhattacharyya and Chakraborty, 2005). In real sense, it refers to a holistic production and enhances ago-ecosystem health, including biodiversity, biological cycles, and soil biological activity. Organic agriculture in India has its roots in traditional agricultural practices that evolved in farming communities over the millennium. It accentuates the use of management practices in favour to the use of off-farm inputs, taking into account that regional situation involve locally adapted system. India is gifted with a variety of type of naturally available organic form of nutrients in different parts of the country and it will aid for organic cultivation of crops significantly.

Organic farming is a method of farming system which primarily aimed at cultivating the land and raising crops in such a way, as to keep the soil alive and in good health by use of organic wastes (crop, animal and farm wastes, aquatic wastes) and other biological materials along with beneficial microbes (biofertilizers) to release nutrients to crops for increased sustainable production in an ecofriendly pollution free environment (Narayanan 2005).

As per the definition of the United States Department of Agriculture (USDA), study team on organic farming "organic farming is a system which avoids or largely excludes the 
use of synthetic inputs (such as fertilizers, pesticides, hormones, feed additives etc.) and to the maximum extent feasible rely upon crop rotations, crop residues, animal manures, off-farm organic waste, mineral grade rock additives and biological system of nutrient mobilization and plant protection".

FAO suggested that "Organic agriculture is a unique production management system which promotes and enhances agro-ecosystem health, including biodiversity, biological cycles and soil biological activity, and this is accomplished by using on-farm agronomic, biological and mechanical methods in exclusion of all synthetic off-farm inputs".

The key objectivity of organic farming resides on development of a self-sustainable farming system in harmony with nature which delivers ecologically and economically sustainable pure food with enrichment of surrounding biodiversity and its entire components.

National Program on Organic Production (NPOP), India defined organic agriculture as "Organic agriculture is a system of farm design and management to create an ecosystem which can achieve sustainable productivity without the use of artificial external inputs such as chemical fertilizers and pesticides."

From the above definitions, it is clear that philosophically organic farming means 'farming in spirits of organic relationship. In this system, 'everything is linked with everything else'. Since, organic farming means placing farming on vital relationship with all essential components and it is the whole of these relationships that is the bed rock of organic farming.

\section{Present status of organic farming}

India stands a distinctive position among 172 countries doing organic agriculture. India has
699 processors, 669 exporters, 650000 organic producer practicing organic cultivation in 720000 hectares[9]. India produced roughly 1.35 million MT (2015-16) of certified organic products which consists of all varieties of food products namely Cereals \& Millets, Sugarcane, Pulses, Cotton, Oil Seeds, Vegetables, Fruits, Medicinal Plants, Spices, Tea, and Coffee etc. The production is not restricted to the edible part but also produces organic cotton, functional food products, fiber, etc.

As per the available statistics, India's rank in terms of World's Organic Agricultural land was $9^{\text {th }}$ and in terms of total number of producers was $1^{\text {st }}$ as per 2018 data (FiBLIFOAM 2018).

\section{Area}

As on $31^{\text {st }}$ March 2018, total area under organic certification process (registered under NPOP) is 3.56 million Hectare (2017-18). This includes 1.78 million ha $(50 \%)$ cultivable area and another 1.78 million hectare $(50 \%)$ for wild harvest collection. Among all the states, Madhya Pradesh has covered largest area under organic certification followed by Rajasthan, Maharashtra and Uttar Pradesh. During 2016, Sikkim has achieved a remarkable distinction of converting its entire cultivable land (more than $76000 \mathrm{ha})$ under organic certification (APEDA, 2020).

\section{Production}

India produced around 1.70 million MT (2017-18) of certified organic products which includes all varieties of food products namely Oil Seeds, Sugar cane, Cereals \& Millets, Cotton, Pulses, Medicinal Plants, Tea, Fruits, Spices, Dry Fruits, Vegetables, Coffee etc. The production is not limited to the edible sector but also produces organic cotton fiber, functional food products etc. Among different 
states Madhya Pradesh is the largest producer followed by Maharashtra, Karnataka, Uttar Pradesh and Rajasthan. In terms of commodities Oil seeds are the single largest category followed by Sugar crops, Cereals and Millets, Fiber crops, Pulses, Medicinal, Herbal and Aromatic plants and Spices and Condiments.

\section{Exports}

The total volume of export during 2017-18 was 4.58 lakh MT. The organic food export realization was around INR 3453.48 crore (515.44 million USD). Organic products are exported to USA, European Union, Canada, Switzerland, Australia, Israel, South Korea, Vietnam, New Zealand, Japan etc. In terms of export value realization Oilseeds (47.6\%) lead among the products followed by Cereals and millets (10.4\%), Plantation crop products such as Tea and Coffee $(8.96 \%)$, Dry fruits $(8.88 \%)$, Spices and condiments $(7.76 \%)$ and others.

\section{Potential areas of organic farming}

Whatever small organic farming that is being grown in India likely to be taken up mainly as part of contract farming and it may be promoted in selected rainfed area and for export oriented crops in India (Marwaha and Jat 2004). Soil and climate conditions in India's rainfed make them typically well fitted to organic farming.

Many states in India had already begun steps to promote the organic agriculture in the farming society. Amongst the states, Madhya Pradesh took advance lead in organic farming followed by Uttarakhand (declared as organic state) and others states.

As far as potential areas are concerned three priority areas have been identified: Category I, Category II and Category III.
Category I: Regions where fertilizers and other agrochemicals consumption is very less. These areas are in Assam and other northeastern states, Jharkhand, Orissa, Jammu \& Kashmir, Himachal Pradesh, Karnataka, Madhya Pradesh, Chhattisgarh and Rajasthan.

Category II: Regions under rainfed and hilly areas provide great opportunity for being transformed into purely organic farming areas. Similarly, some area under plantation crops such as tea, coffee, spices and cashew may be easily brought under the organic farming with a trust on export of organic produce.

Category III: Regions with irrigation and heavy use of fertilizers and other agrochemicals.

Therefore, regions falls under category I and II have a great potential to promote organic agriculture in India.

\section{Organic farming: Myth and reality}

\section{Can organic farming feed the World population?}

The responsibility of organic farming in food security is an arguable issue considering the crop productivity loss and increasing cost of production. Hypothetically, organic farming is the paramount to attain ecologically and economically sustainable crop production and several scientific studies have also been supporting the facts with encouraging consequences in contrast to conventional farming.

Conversely, technological breakthrough to practically demonstrate large extent economically sustainable organic production without time loss is still at large. 
Does organic means free of pesticide/chemical residues?

Studies carried out by various certification agencies indicate either no or very low levels (below detectable limits) of pesticides and other contaminants in organic food product. Residue found in organic product primarily results due to drift from conventional farms. According to an USDA survey, about $21 \%$ of the organic samples had detectable residues(Savage 2016). However, organic food products are definitely safer in terms of toxic residue, though there are few incidents of malpractice and violation, which need to be checked.

Do organic products taste better than conventional products?

According to Yadav 2010, such quality parameters like flavouring ingredients, oils and other taste giving components have been found to be higher inorganic products.

As per report, high yields achieved today in some fruit and vegetable crops with higher chemical fertilizers and other inputs under conventional farming have likely come at the expense of crop nutritional and organoleptic quality (Theuer, 2006).

Does organic products increase the risk of food poisoning?

Yadav (2010) reported that organic cultivation largely depends on higher use of organic manures. Thus, it is assumed that they pose higher risk of contamination.

Though, majority of the experimental results conclude that there is no threat of any food poisoning or bacterial infection through organic products. They are as safe as any other products produced by any other system.

\section{Does organic products contain more} nutrition?

There is a scientific contest concerning the nutrition quality of organic food in contrast to conventionally grown food. A meticulous analysis made by Heaton (2001) indicated that organic food was having higher nutrientsin $43 \%$ cases, equal in $45 \%$ cases and lower nutrients in $11 \%$ cases compared to conventionally grown foods. In India, Bera et al., (2013) and Seal et al., (2017) observed relatively higher vitamin $\mathrm{C}$ and polyphenol content in the organically grown potato and tea, respectively.

\section{Canorganic sources meet entirely nutrient} requirements of crops?

The fundamental prerequisite in organic farming is to enhance input use efficiency at each corner of the farm operations. This is accomplished partly through reducing losses and adoption of new technologies for enrichment of nutrient content in manure as well as enhancing nutrient uptake and utilization efficiency of plant with scientific plant management practice. According to a conservative estimate, if we convert major part of the bio-waste generated in India to organic manure; the manure produced would be about 440 million tonnes per year (Ramaswami, 1999). Tapping these resources and converting it to organic manure with technological advances, and step wise planning for resource regeneration will help to step forward towards self-dependency in organic nutrient management.

\section{Is it possible to manage pests and diseases} in organic farming?

Pest management in organic agriculture can be effectively attempted only through improvement of plant health. A healthy plant is less vulnerable to pest and disease 
infestation. Therefore, a most important aim for the organic farmer is to make conditions which keep the plant healthy. Stress weakens the defense mechanisms of plants and makes them easy targets for pests and diseases. Focusing on plant management towards enhancement of its physiological activities also helps to reactivate plant's inherent quality of self- nourishment and selfprotection, which in turn helps to minimize the incidents of pest/disease infestation and thereby effective control utilizing organic pest control alternatives.

\section{Are there any significant environmental benefits of organic farming?}

The environmental costs of conventional agriculture are ample, and the support for important environmental amelioration through switch to organic agriculture is awesome. An evaluation of over 300 published reports showed that out of 18 environmental impacts, organic farming systems performed significantly better in 12 and performed worse in none (Ramesh et al., 2005). But the biggest impact is minimization of pesticide and heavy metal residues in food chain which threaten the human health aspects.

\section{Is organic agriculture economically feasible?}

In presumption, replacement of external inputs by farm-derived resources should lead to reduction in variable input costs under organic management. However, in most cases outsourcing of bulky organic inputs, ineffective pest control and huge production loss increases the cost of production. Also higher requirement of man-days under organic practice adds up the cultivation cost. Technological advances that can permit enough and timely on-farm resource generation and sustain crop productivity can only cut down the production cost.

\section{Future strategies of organic farming in} India

India is balanced for faster growth with the growing domestic market. Victory of organic movement in India relies upon the expansion of its own domestic markets. With the considerable acreage under naturally organic cultivation, India has remarkable potential to grow crops organically and emerge as a major trader of organic products in the global organic market. With this growing demand more and more technological innovation execution in farmers' field will guarantee economically feasible organic agriculture and aid in its adoption by the common farmers even without any subsidy scheme or guaranteed premium price.

Considering the increasing awareness about the safety and quality of foods, long term sustainability of the system and accumulating evidences of being equally productive, the organic farming has emerged as an alternative system of farming which not only address the quality and sustainability concerns, but also ensure a debtfree, profitable livelihood option.

It is concluded that there are many aspects to consider in harmonizing the benefits of organic and conventional farming system, and there are no effortless ways to establish a clear 'winner' for all potential farming situations. However, instead of long-lasting the ideologically charged 'organic vs. conventional' debate, we should scientifically evaluate the costs and benefits of different management options. In the conclusion, to realize sustainable food security we will possibly call for different alternatives including organic, conventional, as well as possible 'hybrid' systems to produce more food at affordable costs, ensure livelihoods for farmers, and cut down the environmental costs of agriculture. 


\section{References}

Aktar W, D. Sengupta, Chowdhury. 2009. Impact of pesticides use in agriculture: their benefits and hazards. Interdisc Toxicol. 2(1): 1-12.

APEDA. 2020. Agricultural and Processed food product Export Development Authority, Ministry of Commerce and Industries, GOI, http://apeda.gov.in/apedawebsite/organic/Org anic_Products.htm, 2020.

Bera, R., A. Datta, S. Saha, A. Seal, A.K. Dolui, A.K. Chatterjee, R.K. Sarkar, G.C. De, A.K Barik, D. Mazumdar. 2013. Need for a comprehensive approach to ensure sustainable and cost-effective organic tea cultivation - An experience from Model Farm Maud T.E. (Assam), under FAO-CFC-TBI Project in National Seminar On "Organic Tea', Organized by: Tea Research Association, Toklai Experimental Station, Assam, \& Tea Board of India, January 8, 2013.

Bhattacharyya, P., G. Chakraborty. 2005. Current Status of Organic Farming in India and other Countries. Indian Journal of Fertilisers, 1(9): 111-123.

Chitale, S. S.K. Bhoi, A. Tiwari. 2012. Organic rice production technology. Model training course on rice production technology, Pp. 2229.

FiBL2018. IFOAM Survey, Organic Agriculture Worldwide: Current Statistics, 2014 Helga Willer, Research Institute of Organic Agriculture (FiBL), Frick, Switzerland.

Marwaha BC, S.L. Jat. 2004. Statistics and scope of organic farming in India. Fert News. 49(11): 41-48.

Narayanan, S. 2005. Organic farming in India: Relevance, problems and constraints. Deportment of Economic Analysis and Research, Notional Bonk for Agriculture and Rural Development. Mumbai.
Ramaswami, P.P. 1999. Recycling of agricultural and agro industry wastes for Sustainable agricultural production. Journal of Indian Society of Soil Science. 47: 661- 665

Ramesh, P., M. Singh, A. SubbaRao. 2005. Organic farming: Its relevance to the Indian Context. Current Science. 88(4): 561-565.

Roychowdhury, R., M.R.A. Gawwad, U. Banerjee, S. Bishnu, J. Tah, Status. 2013. Trends and Prospects of Organic Farming in India: A Review. Journal of Plant Biology Research, 2(2): 38-48.

Savage, S., 2016. USDA data on 370 crops: Why organic farming has lower yields. Genetic Literacy Project. Available at https://geneticliteracyproject.org/2016/09/16/ usdadata-370-crops-organic-farming-loweryields.

Seal, A..R. Bera, A. Datta, S. Saha, R.R. Chowdhury, K. Sengupta, A.K. Barik, A.K. Chatterjee. 2017. Evaluation of an organic package of practice towards integrated management of Solanum tuberosum and its comparison with conventional farming in terms of yield, quality, energy efficiency and economics, Actaagriculturae Slovenica 109: 363-382.

Theuer, R.C., 2006. Do organic fruits and vegetables taste better than conventional fruits and vegetables? State of the Science Review: Taste of organic food. The Organic Centre. www.organic-center.org

Venkateswarlu, B, S.S. Balloli, Y.S. Ramakrishna. 2008. Organic farming in rainfed agriculture: Opportunities and constraints, Central Research Institute for Dryland Agriculture, Hyderabad, pp. 185.

Yadav, A.K., 2010.Organic Agriculture (Concept, Scenario, Principals and Practices), National Project on Organic farming Department of Agriculture and Cooperation, Govt. of India. Available at http://ncof.dacnet.nic.in

\section{How to cite this article:}

Prakash Yadav, T. Pandiaraj, Vimlesh Kumar, Vikash Yadav and Priyanka Singh. 2020. Concepts, Present Status, Prospective and Myth and Reality of Organic Farming with Special Reference to Indian Context. Int.J.Curr.Microbiol.App.Sci. 9(08): 3742-3748. doi: https://doi.org/10.20546/ijcmas.2020.908.432 